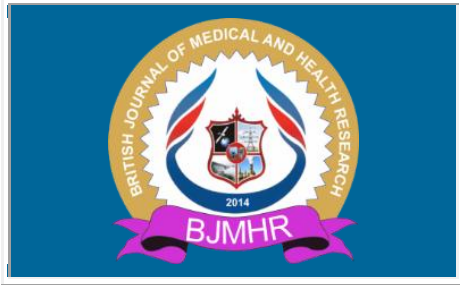

\title{
BJMHR
}

British Journal of Medical and Health Research

Journal home page: www.bjmhr.com

\section{Clinical Profile and Treatment Outcome of Carcinoma Breast Patients---Experience From A Tertiary Care Hospital of Western Up}

\author{
Surabhi Gupta, Laxman Pandey \\ S.N.Medical College,Agra
}

\section{ABSTRACT}

The epidemiological data, management strategies and treatment outcomes for carcinoma breast patients were analyzed in patients admitted to a tertiary care hospital of western up. Hospital records of 399 patients admitted for over a period of five years (January 2011 to December 2015) were used for data analysis. The maximum no. of pts presented was of 4049 yrs age group (41.35\%).66.6\% pts were postmenopausal. The most common complaint was painless lump. Most of the patients (48.62\%) presented to clinician after $1 \mathrm{yr}$ of developing symptoms and only $5.51 \%$ pts within 3 months of onset of symptoms. $68.41 \%$ pts presented as post op cases including residual and recurrent disease while $29.32 \%$ pts presented as locally advanced breast cancer. Familial breast cancer was very uncommon. Left sided breast cancer was slightly preponderant. The most common histology was infiltrating duct carcinoma.38.23\% pts received adjuvant radiotherapy after receiving adjuvant chemotherapy. $16.99 \%$ pts lost to follow up after completion of treatment. The $2 \mathrm{yr}$ DFS in the 3 arms $(25 \#, 20 \#, 17 \#)$ was $44.68 \%, 51.61 \%$ and $50 \%$ respectively, while $2 \mathrm{yrs}$ overall survival was $61.7 \%, 51.61 \%$ and $75 \%$ respectively. Loco-regional failures were seen in $0 \%, 3.22 \%$ and $12.5 \%$ cases and distal recurrence in $27.65 \%, 9.67 \%$ and 12.5 consecutively. While 5 yrs overall survival in $25 \#$ vs. $20 \#$ arm was $9.7 \%$ vs. $4 \%$. Mean age of presentation was found to be lower compared to the western world, with an average one decade before as mentioned in literature. Most of the patients were not having any risk factors except being female. Most of the patients got defaulted in view of long waiting list for radiotherapy so we are trying to switchover conventional protocol to hypo-fractionated Radiotherapy protocol so more no. of pts can be benefitted particularly in a government setup.

Keywords: Breast cancer, risk factors, clinical profile, hypo fractionation Radiotherapy 


\section{INTRODUCTION}

Breast cancer in female is a major medical problem. World wide it is the most common form of cancer in females, affecting at some time in their lives approximately one out of nine to thirteen women who reach age ninety in the western world. Presently, 75,000 new cases occur in India each year ${ }^{1}$. The incidence of breast cancer is raising steadily over time. This seems to be closely related to industrial development and changing life style. In India it is the second most common cancer after cervix accounting for $19 \%$ of the total cancer burden ${ }^{2}$ The disease is higher in urban areas rather than rural areas, with Delhi having the highest incidence in the country followed by Mumbai, Chennai and Bangalore ${ }^{3}$. The risk of breast cancer increase with age. In the west only $<1 \%$ cases are seen in women less than 30 years, about $6-7 \%$ in between $30-40$ years. This disease is more common in women with better socio economic status due to unknown reasons but life style differences and dietary habits are said to be risk factors. The relative risk of carcinoma breast is 1.7 in a woman who has an immediate relative i.e. mother, daughter or sister having this problem. If these relatives have got the disease onset in pre-menopausal age, the risk is increased three folds while it is 1.5 if the onset is in post-menopausal age. The lifelong exposure to female reproductive hormones is known to be associated with increased risk of breast cancer. Similarly there has been known association between plasma estrogen levels \& breast cancer.

Women having one full term pregnancy have a $25 \%$ decrease in the risk of breast cancer in contrast to nulliparous females. There is also evidence that women having more children are more protected against breast cancer. Longer duration of lactation also reduces the breast cancer incidence. ${ }^{4,5}$ It was supposed for long that the breast cancer risk increases with high intake of dietary fat. There may be a protective effect of vegetables intake .In a study by American Cancer Society the risk of mortality due to Ca breast was significantly increased due to obesity. Physical exercise may reduce breast cancer risk. This reduction has been seen both in pre \& post menopausal women. Breast cancer is more common on the left side as compared to right due to unknown reasons. It is most common in upper outer quadrant followed by central area, upper inner, lower outer \& lower inner quadrants. The usual presentation is with a painless lump in the breast, but there are many differences between the presentations of breast cancer in developed and under developed areas in the world. It is not common to see large tumors with skin ulcerations, bleeding and peau'd orange presentation in the countries with good socio economic status, while it is a common finding in the poor countries. Similarly it is a routine to pick up very early suspicious lesions in the developed countries where screening mammography are carried out effectively. 
Multivariate analysis have shown that a longer duration of symptoms had a highly significant adverse effect on survival. ${ }^{6}$ The presence of hormone receptors on the tumor tissue predicts the benefit a patient can get from hormone treatment. HER-2 positive tumours are generally related with comparatively poor prognosis than HER-2 negative tumours. Mastectomy is the most common procedure carried out in most of the parts in India .As most of the patient present after mastectomy with or without axillary clearance. If axillary clearance is there it is usually incomplete so keeping all the points in view all pts receive adjuvant loco-regional radiotherapy to chest wall ,axilla and supraclavicular region and in few cases internal mammary chain also in our set up. The conventional dose is 5000cGy in 5wks @2Gy per fraction and is widely acceptable protocol. Due to increase in incidence of breast cancer and long waiting list for radiotherapy we are trying to switch over this conventional protocol into hypo- fractionation protocol .A hypo fractionated protocol means reducing no of fractions and overall treatment time while increasing dose per fraction. At Christie Hospital Manchester there has been a routine to deliver 5000 -5500 CGy in 15-16 fractions for most of the tumors for decades \& they have shown equivalent results in most of the settings. For breast cancer they use $4000 \mathrm{CGy}$ in 3 weeks i.e. 15 fractions with good results.

Carcinoma breast continues to be the focus of intense basic and clinical research. Hence, this retrospective study was carried out to know the epidemiology, clinical presentation, risk factors and management strategies for breast patients in a tertiary government setup.

\section{MATERIALS AND METHOD:}

A total of 467 primary breast cancer patients were registered in the department over a fiveyear period (January 2011 - December 2015) out of which 399 patients were admitted for the treatment and were taken up for study. A detailed analysis of patients was done according to a planned proforma. The required information was collected from the medical records of the patients submitted in the department. Radiotherapy was delivered by $\mathrm{Co}^{60}$ teletherapy machine by 3 field/4field techniques.

In this study we have tried to represent the clinical profile of breast cancer pts in terms of patient characteristics, tumor characteristics, duration of symptoms, and way of presentation and pattern of treatment received, treatment outcome and follow up pattern in a tertiary government setup.

The purpose of this study was to see the epidemiological pattern, presentation pattern of ca Breast patients, treatment outcome of different radiotherapy fractionations practiced in the department in terms of loco-regional recurrence, distant recurrence, $2 \mathrm{yr}$ overall survival, Disease free survival,5yr overall survival and to search out the cause of defaulter of pts from treatment. 


\section{RESULTS AND DISCUSSION}

Out of 467 patients registered in the department, 399 pts were evaluable for the study that means only $85.43 \%$ pts received treatment after enrolment. The maximum no. of pts presented was of 40-49 yrs age group (41.35\%) while $2^{\text {nd }}$ decade pts were $3.5 \% .66 .6 \%$ pts were postmenopausal.

The most common complaint was painless lump in the breast. Most of the patients $(48.62 \%)$ presented to clinician after $1 \mathrm{yr}$ of developing symptoms and only 5.51\% pts presented within 3 mths of onset of symptoms.62.15\% pts were from rural area of local place.65.65\% patients were having 2 or more para.

Left side lesions were more common than Rt side lesions (52.3\% vs $46.86 \%$ ).Maximum no. of pts were of stage III (64.39\%). In most of the pts (76.19\%) receptor status were not known. In pts whom receptor status was known, triple negative pts were $23.95 \%$ while triple positive were $16.66 \%$.

(Table-1)

$68.41 \%$ pts presented as post-op cases, out of which $16.03 \%$ pts were with post-op residual/recurrent disease while $29.32 \%$ pts presented as locally advanced disease.

Only $36.09 \%$ pts received Neo-adjuvant chemotherapy while $55.13 \%$ pts received adjuvant chemotherapy.(Table-2)

Out of 399 pts, only 153 pts $(38.34 \%)$ received radiotherapy in the dept. out of which $88.88 \%$ received radical radiotherapy while $7.18 \%$ pts received palliative radiotherapy.62.49\%pts could get radiotherapy after 6 months of surgery due to long waiting list for radiotherapy.

Adjuvant radiotherapy received as per 25\#, 20\#, 17\# and 15\# protocol by $42.64 \%, 33.08 \%$, $12.5 \%$ and $11.76 \%$ pts respectively. (TABLE-3)

AS 15\# protocol pts completed only $1 \mathrm{yr}$ of follow up so this arm was not included in $2 \mathrm{yr}$ survival analysis. The $2 \mathrm{yr}$ DFS in the $3 \operatorname{arms}(25 \#, 20 \#$ and17\#) was $44.68 \%, 51.61 \%$ and $50 \%$ respectively while 2 yrs overall survival was $61.7 \%, 51.61 \%$ and $75 \%$ respectively.. Locoregional failure are seen in $0 \%, 3.22 \%$ and $12.5 \%$ cases while distal recurrence in $27.65 \%, 9.67 \%$ and $12.5 \%$ pts respectively.

While comparing 5yrs overall survival it is $9.7 \%$ vs. $4 \%$.( $25 \#$ vs. $20 \#)$

TABLE-4)

Table 1: Patient's characteristics

\begin{tabular}{lll}
\hline Age(yrs) & No of pts & $\%$ \\
\hline $20-29$ & 14 & $3.50 \%$ \\
$30-39$ & 50 & $12.53 \%$ \\
$40-49$ & 165 & $41.35 \%$ \\
$50-59$ & 102 & $25.56 \%$
\end{tabular}




\begin{tabular}{lll}
$60-69$ & 50 & $12.53 \%$ \\
$70-79$ & 17 & $4.26 \%$ \\
$=/>80$ & 1 & $0.25 \%$ \\
Premenopausal & 133 & $33.33 \%$ \\
postmenopausal & 266 & $66.66 \%$ \\
Local place & 248 & $62.15 \%$ \\
Nearby districts & 127 & $31.83 \%$ \\
Remote area & 24 & $6.01 \%$ \\
$=/<2$ & 78 & $19.54 \%$ \\
>2-4 & 161 & $40.35 \%$ \\
$>4$ & 101 & $25.3 \%$ \\
nullipara & 59 & $14.7 \%$ \\
Rt side lesion & 187 & $46.86 \%$ \\
Lt side lesion & 209 & $52.3 \%$ \\
B/L & 3 & $0.75 \%$ \\
Presentation & & \\
Lump & 321 & $80.45 \%$ \\
Lump with pain & 68 & $17.04 \%$ \\
Lump with pain and d/s & 10 & $2.5 \%$ \\
Duration of symptoms & & \\
<3mth & 22 & $5.51 \%$ \\
3-5mth & 63 & $15.78 \%$ \\
6-8mth & 79 & $19.79 \%$ \\
9-11mth & 41 & $10.27 \%$ \\
>12mth & 194 & $48.62 \%$ \\
\hline
\end{tabular}

\section{Table 2: Disease presentation}

\begin{tabular}{lll}
\hline As per presentation & & \\
Postop NED & 209 & $52.38 \%$ \\
POSTOP residual & 36 & $9.52 \%$ \\
Postop recurrence & 26 & $6.51 \%$ \\
LABC & 117 & $29.32 \%$ \\
Metastatic & 11 & $2.75 \%$ \\
As per staging & & \\
Stage I & 7 & $2.04 \%$ \\
STAGE IIA & 44 & $12.8 \%$ \\
STAGE IIB & 61 & $17.7 \%$ \\
STAGE IIIA & 80 & $23.32 \%$ \\
STAGE IIIB & 115 & $33.52 \%$ \\
STAGE III C & 26 & $7.55 \%$ \\
STAGE IV & 10 & $2.91 \%$ \\
NA & 56 & $14.03 \%$ \\
Receptor Status & & \\
unknown RECEPTOR status & 304 & $76.19 \%$ \\
known receptor status & 96 & $24.06 \%$ \\
ER/PR/HER+ve & 16 & $16.66 \%$ \\
ER/PR/HER -ve & 23 & $23.95 \%$ \\
ER/PR+ve & 11 & $11.45 \%$ \\
ER/PR-ve & 6 & $6.2 \%$ \\
Er+ve/Pr-ve & 14 & $14.54 \%$ \\
Er-ve/Pr+ve & 4 & $4.16 \%$ \\
ER+/Pr+/HER- & 11 & $11.45 \%$ \\
ER-/PR-/HER+ & 10 & $10.4 \%$ \\
\hline
\end{tabular}


Table-3: As per Treatment Received

\begin{tabular}{lll}
\hline Chemotherapy & & \\
\hline NACT Received & 144 & $36.09 \%$ \\
Adjuvant CT Received & 220 & $55.13 \%$ \\
Radiotherapy & & \\
Palliative & 27 & $17.64 \% \%$ \\
Radical +Palliative Both & 11 & \\
Radical RT(adjuvant) & 136 & $88.88 \%$ \\
50Gy/25\# & 58 & $42.64 \%$ \\
45Gy/20\# & 45 & $33.08 \%$ \\
4250CGY/17\# & 17 & $12.5 \%$ \\
40GY/15\# & 16 & $11.76 \%$ \\
GAP between Sx and RT & & \\
<3mth & 7 & $5.16 \%$ \\
3-6mth & 52 & $38.23 \%$ \\
7-9mth & 44 & $32.35 \%$ \\
>9mth & 41 & $30.14 \%$ \\
\hline
\end{tabular}


Table 4: End points results after deducting lost to follow-up pts

\begin{tabular}{|l|l|l|l|l|l|l|l|l|l|l|l|}
\hline $\begin{array}{l}\text { Fractio } \\
\text { nations }\end{array}$ & $\begin{array}{l}\text { No of } \\
\text { pts(enr } \\
\text { olled) }\end{array}$ & $\begin{array}{l}\text { Evaluable } \\
\text { pts }\end{array}$ & 1yr DFS & 2yrDFS & Iyr OS & 2yr OS & $\begin{array}{l}\text { Loco-regional } \\
\text { recurrence }\end{array}$ & $\begin{array}{l}\text { Distant } \\
\text { recurrence }\end{array}$ & Death & 3yr os & 5yros \\
\hline $25 \#$ & 57 & 47 & $\begin{array}{l}32 \\
(68.08 \%)\end{array}$ & $\begin{array}{l}21 \\
(44.68 \%)\end{array}$ & $\begin{array}{l}45 \\
(95.74 \%)\end{array}$ & $\begin{array}{l}29 \\
(61.7 \%)\end{array}$ & $\begin{array}{l}0 \\
(0 \%)\end{array}$ & $\begin{array}{l}13 \\
(27.65 \%)\end{array}$ & $\begin{array}{l}1 \\
(2.12 \%)\end{array}$ & $\begin{array}{l}13 / 41 \\
(31.7 \%)\end{array}$ & $\begin{array}{l}4 / 41 \\
(9.75 \%)\end{array}$ \\
\hline $20 \#$ & 45 & 31 & $\begin{array}{l}26 \\
(83.87 \%)\end{array}$ & $\begin{array}{l}16 \\
(51.61 \%)\end{array}$ & $\begin{array}{l}31 \\
(100 \%)\end{array}$ & $\begin{array}{l}16 \\
(51.61 \%)\end{array}$ & $\begin{array}{l}1 \\
(3.22 \%)\end{array}$ & $\begin{array}{l}3 \\
(9.67 \%)\end{array}$ & $\begin{array}{l}1 \\
(3.22 \%)\end{array}$ & $\begin{array}{l}10 / 25 \\
(40 \%)\end{array}$ & $\begin{array}{l}1 \\
(4 \%)\end{array}$ \\
\hline $17 \#$ & 17 & 16 & $\begin{array}{l}13 \\
(81.25 \%)\end{array}$ & $\begin{array}{l}8 \\
(50 \%)\end{array}$ & $\begin{array}{l}16 \\
(100 \%)\end{array}$ & $\begin{array}{l}12 \\
(75 \%)\end{array}$ & $\begin{array}{l}2 \\
(12.5 \%)\end{array}$ & $\begin{array}{l}2 \\
(12.5 \%)\end{array}$ & 0 & $\begin{array}{l}7 / 14 \\
(50 \%)\end{array}$ & 0 \\
\hline $15 \#$ & 15 & 14 & $\begin{array}{l}11 \\
(78.57 \%)\end{array}$ & - & $\begin{array}{l}14 \\
(100 \%)\end{array}$ & - & $\begin{array}{l}0 \\
(0 \%)\end{array}$ & $\begin{array}{l}3 \\
(21.42 \%)\end{array}$ & 0 & 0 & 0 \\
\hline
\end{tabular}


The purpose of this analysis was to study the clinical profile of breast cancer patients at a tertiary care hospital in western UP. The maximum no. of pts presented was of 40-49 yrs age group (41.35\%) as also reported in studies from India and other Asian countries ${ }^{1,7,8}$ and this is one decade earlier than western countries where carcinoma is predominantly seen in the fifth and sixth decade $e^{9,10,11,12}$. Out of the entire patient, $62.15 \%$ were from rural area of local district. However, other reports from India as well as western world show higher incidence in urban population compared to the rural population ${ }^{4,12}$. The difference may be due to lack of health facilities in the villages. The other aspect may be being a government setup most patients attending the hospital belong to rural background due to economic constrains. Furthermore, the consolidated report of the Indian Council of Medical Research (ICMR) on Population Based Cancer Registry (PBCR) cites that 70 - 80\% of India's population resides in rural areas and the currently available data is mainly from the urban registries, therefore, to estimate the load of cancer is difficult. ${ }^{6}$ Painless lump in the breast was the chief presenting complaint in a majority of the patients $(80.45 \%)$, as also reported in various studies ${ }^{13,14}$, while $2.5 \%$ pts presented with complaints of lump with discharge.

Most of the patients (48.62\%) presented to clinician after $1 \mathrm{yr}$ of developing symptoms and this pattern shows that pt usually not present until symptoms become very stressful to the pts. This is because of lack of public awareness and negligence regarding their health. The left breast carcinoma incidence was more than right side collaborating with the previous reports ${ }^{15,16,17,18}$.. Only $14.7 \%$ of the patients were nulliparous, whereas, $65.6 \%$ patients were with more than 2 children. However, other reports indicate higher incidence of breast carcinoma in nulliparous females ${ }^{3,20,21}$, Incidence of breast carcinoma was more in postmenopausal $(66.6 \%)$ patients. The earlier published reports also show that the risk of breast carcinoma increases with increasing age of menopau, possibly because the women are exposed to hormones for a longer duration. ${ }^{22,23,24}$ Maximum no. of (64.39\%) patients presented in Stage III disease in accordance with other reports from India..76.19\% patients were not able to afford expenses of Receptor studies. Receptor status was known in only $24.06 \%$ patients, out of which triple negative pts were maximum i.e. $23.95 \%$.

Most of the patient presented to us as post-op cases. Apprx $16.03 \%$ patients presented with either post-op residual disease or recurrent disease. Neoadjuvant chemotherapy was received by $36.09 \%$ pts and most of the pts were given FEC/FAC regimen .

Apprx 55.13\% patients received adjuvant chemotherapy in the department. Only $38.34 \%$ patients turned up for Radiotherapy treatment out of which $88.88 \%$ patients received adjuvant loco-regional radiotherapy as per departmental protocol. The cause of defaulter of most of patients from radiotherapy may be the long waiting list due to resource insufficiency as per 
patients load as most of the pts (62.49\%) could get radiotherapy after 6 months of surgery. Conventional breast and/or chest wall irradiation uses 2 Gy daily fraction, for 5-6 weeks. Such a long treatment schedule has major implications on both patient quality of life and Radiotherapy departments ${ }^{2,3}$ Some investigators have hypothesized that breast cancer is as sensitive as normal breast tissue to fraction size. According to the hypothesis, small fraction sizes of 2.0 Gy or less offer no therapeutic advantage, and a more effective strategy would be to deliver fewer, larger fractions that result in a lower total radiation dose [1]. This short (hypofractionated) RT schedule would be more convenient for patients, especially those coming from remote areas and for health care providers, as it would increase the turnover in Radiotherapy departments.

Keeping in mind the defaulter of pts and treating the patients with limited resources we have tried to switch over conventional radiotherapy $(50 \mathrm{~Gy} / 25 \# / 5 \mathrm{wks})$ plan to hypo fractionation radiotherapy i.e. from $25 \#$ to $20 \#$ and $17 \#$ and now $15 \#$. The $2 \mathrm{yr}$ DFS in the 3 arms (25\#, 20\# and17\#) was $44.68 \%, 51.61 \%$ and $50 \%$ respectively, which is statistically comparable, while 2 yrs overall survival was $61.7 \%, 51.61 \%$ and $75 \%$ respectively. Loco-regional failure are seen in $0 \%, 3.22 \%$ and $12.5 \%$ cases while distal recurrence in $27.65 \%, 9.67 \%$ and $12.5 \%$ pts. While comparing 5 yrs overall survival it is $9.7 \%$ vs. $4 \%$.( $25 \#$ vs. $20 \#) .1 \mathrm{yr}$ disease survival results of 15\# protocols are encouraging and rate of defaulter from radiotherapy is also reduced when compared to previous yrs.

\section{CONCLUSION}

The mean age of presentation for breast carcinoma is a decade earlier in our patients compared to patients from the west. Hence, mammography as a screening tool less sensitive due to higher density of breast tissue at younger age. Due to economic constrains most people are unable to afford mammography. Thus there is a need for developing other cost-effective screening modalities for breast cancer in addition to propagating breast self-examination in masses, for early detection. Hypo fractionation Radiotherapy may be a better option for a government set up where pts load is more. .

\section{REFERENCES}

1. Chopra R. The Indian Scene. Journal of Clinical Oncology 2001;19:S106-11.

2. Source $=$ GLOBOCAN 2002, I ARC

3. SOURCE $=$ NATIONAL CANCER REGISTRY 2001, INDIA

4. Melbye, Wohlfahrt, Olsen JH et all. Induction abortion and risk of breast cancer. N Engl J Med. 1997 Jan 9;336(2):81-5 
5. Lipworth, Bailey LR, Trichopulos D.History of breast -feeding in relation to breast cancer risk:a review of the epidemiologic literature.J Natl Cancer Inst. 2000 Feb 1892(4):302-12

6. Gupta P, Sharma RG, Verma M. Review of breast cancer cases in Jaipur region. J Indian Med Assoc 2002;100:282-3, 2 86-7.

7. Nouh MA, Ismail H, El-Din NH, El-Bolkainy MN. Lymph node metastasis in breast carcinoma: clinicopathological correlations in 3747 patients. J Egypt Natl Canc Inst 2004;16:50-6.

8. Hospital Episode Statistics Vol. 2 1991/92. Department of Health. London: HMSO, 1995.

9. Anderson WF, Chatterjee N, Ershler WB, Brawley OW. Estrogen receptor breast cancer phenotypes in the Surveillance, Epidemiology, and End Results database. Breast Cancer Res Treat 2002;76:27-36.

10. El-Tamer MB, Wait RB. Age at presentation of African-American and Caucasian breast cancer patients. J Am Coll Surg 1999;188:237-40.

11. Coughlin SS, Thompson TD, Hall HI, Logan P, Uhler RJ. Breast and cervical carcinoma screening practices among women in rural and nonrural areas of the United States, 1998-1999. Cancer 2002;94:2801-12.

12. Raina V, Bhutani M, Bedi R, Sharma A, Deo SV, Shukla NK, et al. Clinical features and prognostic factors of early breast cancer at a major cancer center in North India. Indian J Cancer 2005;42:36-41.

13. Nagpal BL, Singh A, Sehgal RK, Kaur P. Breast cancer in Punjab (a clinicopathological review of 640 cases). J Indian Med Assoc 1980;75:113-6.

14. Hussain MA, Ali S, Tyagi SP, Reza H. Incidence of cancer breast at Aligarh. J Indian Med Assoc 1994;92:296-7.

15. Perkins CI, Hotes J, Kohler BA, Howe HL. Association between breast cancer laterality and tumor location, United States, 1994-1998. Cancer Causes Control 2004; 15:637-45.

16. Seymour I. Schwartz. Breast In. Principles of Surgery. 7 th Edition. McGrawHill.1999. p. 564.

17. Russell RCG, Williams NS, Bulstrode CJK. The breast In. Bailey and Love's Short Practice of Surgery.24 th Edition. Arnold. 2004. p. 837.

18. Lee AH. Why is carcinoma of the breast more frequent in the upper outer quadrant? A case series based on needle core biopsy diagnoses. Breast 2005;14:151-2. 
19. Kelsey JL, Gammon MD, John EM. Reproductive factors and breast cancer. Epidemiol Rev 1993;15:36.

20. Rosner B, Colditz GA, Willett WC. Reproductive Risk factors in a prospective study of breast cancer: the nurses' health study. Am J Epidemiol 1994;139:819.

21. McPherson K, Steel CM, Dixon JM. ABC of breast diseases. Breast cancerepidemiology, risk factors, genetics. BMJ 2000;321:624-8.

22. Alberg AJ, Lam AP, Helzlsouer KJ. Epidemiology, prevention, and early detection of breast cancer. Curr Opin Oncol 1999;11:435-41.

23. Trichopoulos D, MacMahon B, Cole P. Menopause and breast cancer risk. J Natl Cancer Inst1972;48:605-13.

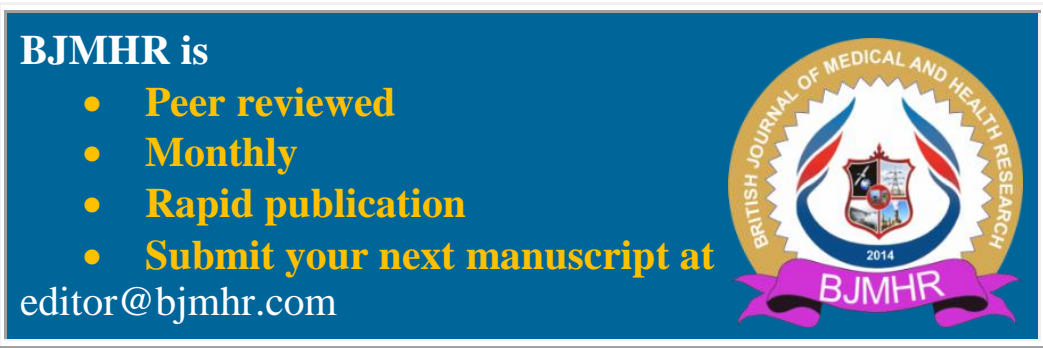

